61 Ikhram Kharis : Comparison Between RunX2 and Osteocalcin Expression Following the Application

\title{
Comparison Between RunX2 and Osteocalcin Expression Following the Application of Demineralized Freeze-Dried Bone Xenograft (DBFX) and Bovine Hydroxyapatite (BHA) and Their Effect on Bone Defect (In vivo Laboratory Experiment)
}

\author{
Ikhram Kharis $^{1 *}$, R. Soesanto ${ }^{2}$, Andra Rizqiawan ${ }^{2}$ \\ ${ }^{1}$ Faculty of Dentistry, Airlangga University \\ ${ }^{2}$ Department of Oral and Maxillofacial Surgery, Airlangga University \\ *Corresponding author: ikhram.kharis@gmail.com
}

\begin{abstract}
The use of biomaterial such as bone graft material is highly needed in oral and maxillofacial surgery to overcome bone defect that happened due to various reasons. One of the bone graft that widely used is bovine hydroxyapatite (BHA). BHA is produced by means of deproteinizing by a high-temperature heating process so that inorganic material of bone is left where the bone architecture is preserved. This material has osteoconductive property because it induces osteoblast activity and new bone formation. DFDBX is a bone graft derived from bovine bone which has undergone the demineralization process and subsequently frozen. Then, it will be exposed to hydrochloric acid until the bone matrix component-related collagen fibril called BMPs. Runt-Related Transcription factor 2 (RUNX2) is a transcription factor which is needed for osteoblast differentiation and it is first detected at preosteoblast. Osteocalcin is exerted during the last stage of differentiation, started at the early stage of mineralization. Objectives to compare the expression of RUNX2 and Osteocalcin following the application of DFDBX and BHA to the bone defect. Methode 30 male New Zealand White Rabbit, 6- months old, 3-3,5kg, divided into 3 groups comprising of 10 animals each, bone defect is created on each animal model. On group 1, DFDBX is applicated, BHA is on group 2, and control group with no graft application. After 2 weeks and 4 weeks following the animal model is terminated to retrieve a bone specimens for Immunohystochemistry examination. Result The expression of RUNX2 following the application of DFDBX and BHA showed a significant difference at week 2 but not showed at week 4 . This research also found that the expression of osteocalcin did not show a significant difference at week 2 but showed a significant difference at week 4. Conclussion This study demonstrate that bone healing process in DFDBX group is more effective than BHA.
\end{abstract}

\section{Keywords: DFDBBX, BHA, RUNX2, osteocalcin, IHC}

\section{INTRODUCTION}

The use of biomaterials in the form of bone grafts is very necessary in the field of oral and maxillofacial surgery to overcome bone defects that can occur due to various reasons. Tooth extraction can cause the remaining alveolar bone 
to become narrow and shortened and is the main cause of jawbone atrophy. To overcome this problem, prior to the installation of dental implants, an alveolar bone grafting procedure must be carried out first to regenerate the existing alveolar bone defects (Lekovic et al., 2007).

Currently, there are 4 types of bone grafts, namely; (1) autograft, bone is taken from the same individual, (2) allograft, bone is taken from another individual of the same species, (3) xenograft, bone is taken from a different species, preserved with ethylene diamine to remove organic and antigenic fractions, (4) alloplasts, bone substitutes and synthetic materials such as hydroxyapatite(Hallman \& Thor, 2008).

The gold standard method for regenerating alveolar bone is autogenous bone graft. Autogenous bone graft is an ideal bone graft because it has the necessary osteogenic, osteoconductive and osteoinductive properties for the bone regeneration process, does not cause transmission of infectious diseases and does not cause an immune response after graft implantation, thereby accelerating the process of union with the new site. Replacement graft materials (bone graft substitutes) have good potential for healing alveolar bone but the quantity is not limited and does not cause morbidity in patients (Babbush, 2001).

Nowadays, many bone tissue engineering procedures have been carried out as an alternative treatment whose available sources are not limited, encouraging the creation of bovine hydroxyapatite (BHA) (Nandi, 2010). Bovine hydroxyapatite (BHA) is produced by deproteinizing with high temperature heating so that what remains is the inorganic (mineral) part where the bone architecture is still preserved.

Recent studies have shown that the osteogenic potential of demineralized freezedried bone xenograft (DFDBX) is related to a number of proteins contained in it and has osteoinduction potential and contains transforming growth factor (TGF ) and BMPs (Plata et al., 2002).

Osteoblasts are single-nucleated cells that function in bone formation and play a role in mineralization of the osteoid matrix. Osteoblasts are formed from osteoprogenitor cells in the bone marrow and the inner lining of the periosteum. The differentiation of these osteoprogenitors is influenced by growth factors, such as bone morphogenetic proteins (BMPs), FGF, PDGF and TGF-b. At the time of differentiation, secrete substances such as alkaline phosphatase, osteocalcin, osteopontin and osteonectin (Agata et al., 2007). Osteocalcin is one of the most abundant non-collagenous bone matrix proteins. Serum osteocalcin shows osteoblast activity. 


\section{METODE}

This study belongs to the Post Test Only Control Group Design research by looking at the expression of RUNX2 and osteocalcin produced in immunohistochemical preparations for mandibular bone defects of rabbits with IHC examination after DFDBX and BHA implantation at 2 and 4 weeks post application. The sample of this study was New Zealand's White Rabbit.

The sample size used in this study was obtained using the following calculation formula:

\section{RESULTS}

This study was conducted to compare the expression of RUNX2 and osteocalcin after application of DFDBX with BHA against mandibular bone defects in rabbits. In this study, the 30 rabbits used were divided into 5 rabbits in each treatment group with DFDBX, the BHA group and the control group without graft with two observation periods, namely the 2 nd and 4 th $(\mathrm{n}-1) \cdot(\mathrm{t}-1) \geq 15$

Description $: \mathrm{n}=$ number of replications $\mathrm{t}=$ number of treatments

The formula for calculating the minimum number of samples listed above can be done because there is no preliminary research. The number of treatments in this study were 6 treatments so that the number of replications (n) was 4 observation times. By considering the possibility of an exclusion sample, the researcher used 5 samples for each treatment. The total number of samples obtained is as many as 30 samples.

weeks.

The results of microscopic examination of osteoblasts with HE (Hematoxylin eosin) staining in the control group without graft, the BHA group and the 2nd and 4th week DFDBX groups are shown in Figure 51. In this image, osteoblasts are depicted as cuboidal or short cylindrical cells with mononuclear nuclei. the blue one with HE painting.
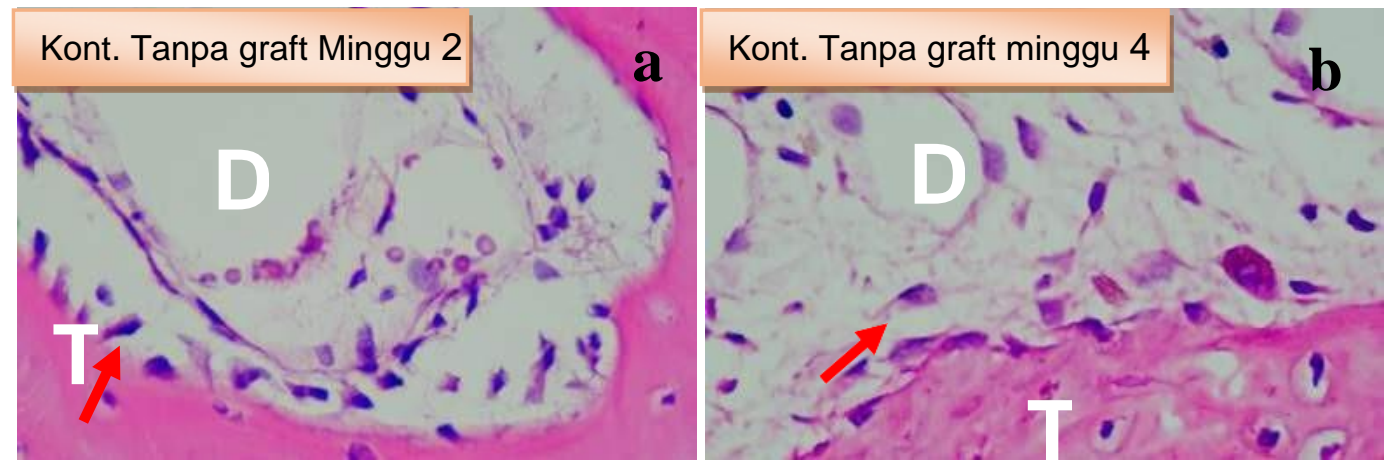

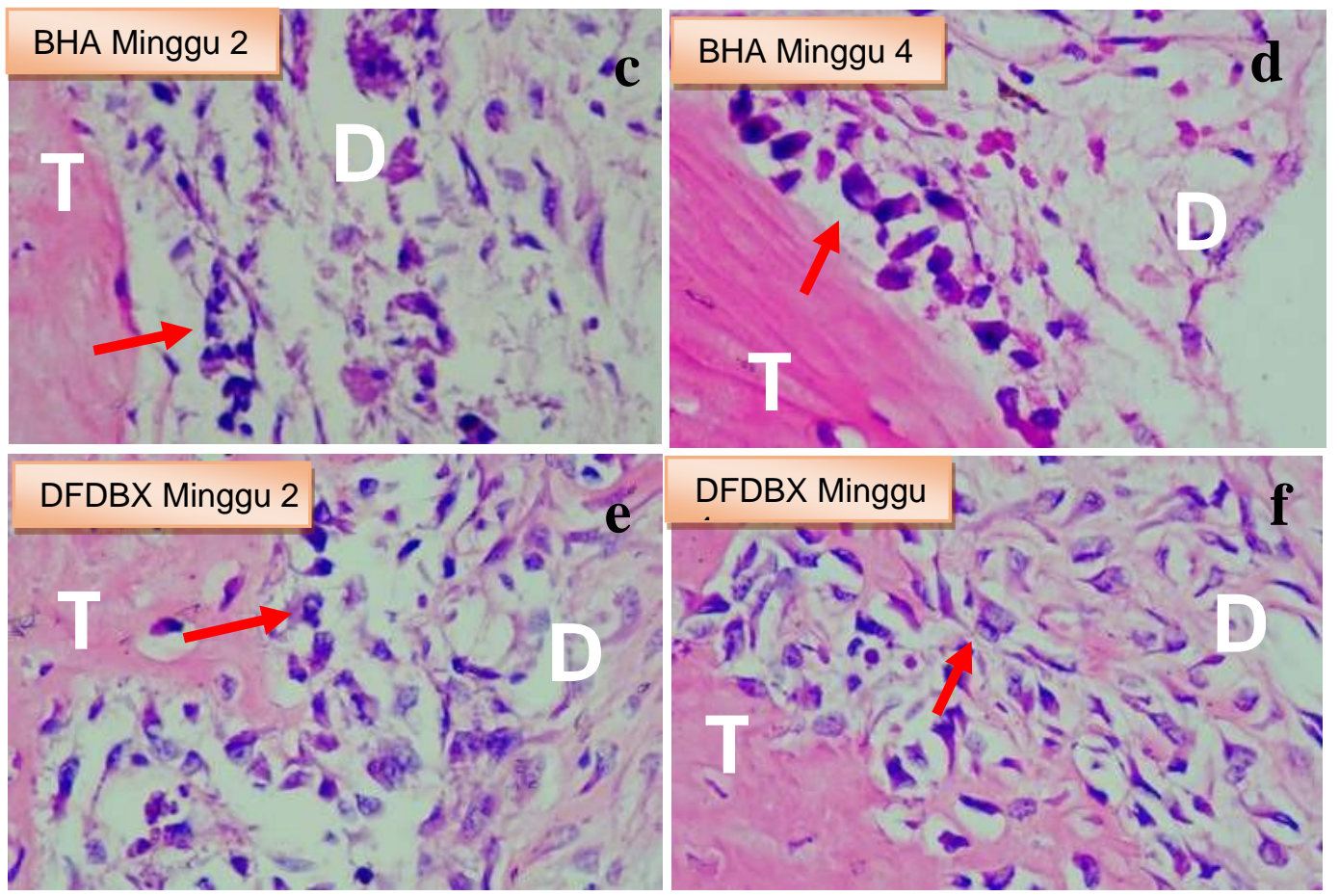

Figure 1 Microscopic view of osteoblasts in the control group without graft, BHA and DFDBX

2nd and 4th weeks. (a) Osteoblasts in the control group without graft week 2 (b)

Osteoblasts in the control group without graft week 4 (c) Osteoblasts in the BHA group week 2 (d) Osteoblasts in the BHA group week 4 (e ) Osteoblasts in the 2nd week DFDBX group (f) Osteoblasts in the 4th week DFDBX group.

The results of microscopic examination of RUNX2 expression in the control group without graft, the BHA group and the DFDBX group at weeks 2 and 4 are shown in Figure 2. The number of osteoblasts expressing RUNX2, indicates a large number of osteoblast deposits in the defect area. The distribution of this osteoblast was most evident in the treatment group with DFDBX, which was then followed by the BHA group and the control group without graft. Osteoblasts expressing RUNX2 are indicated by red arrows.
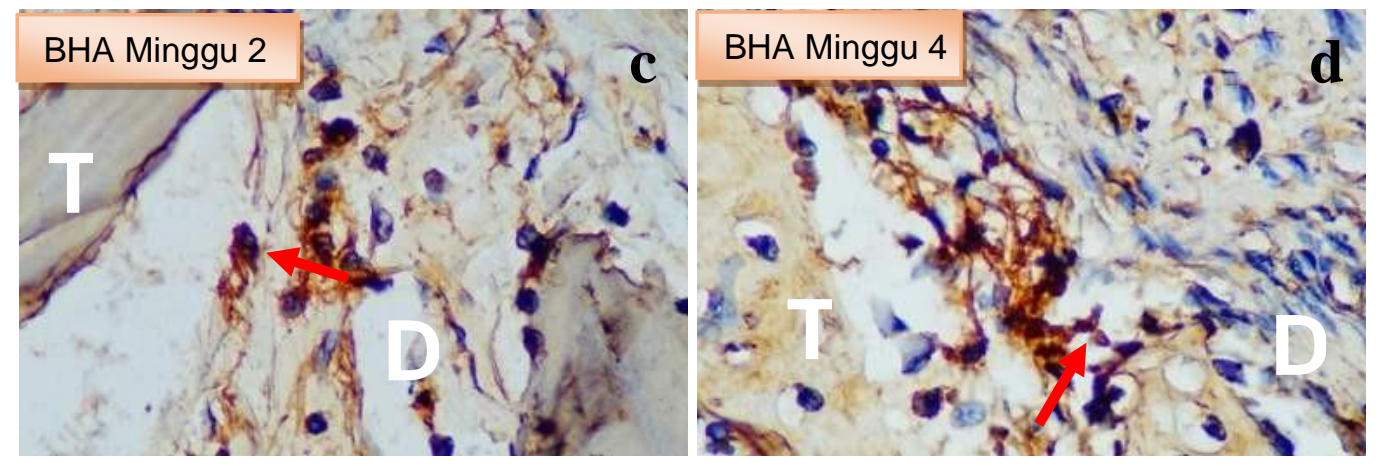


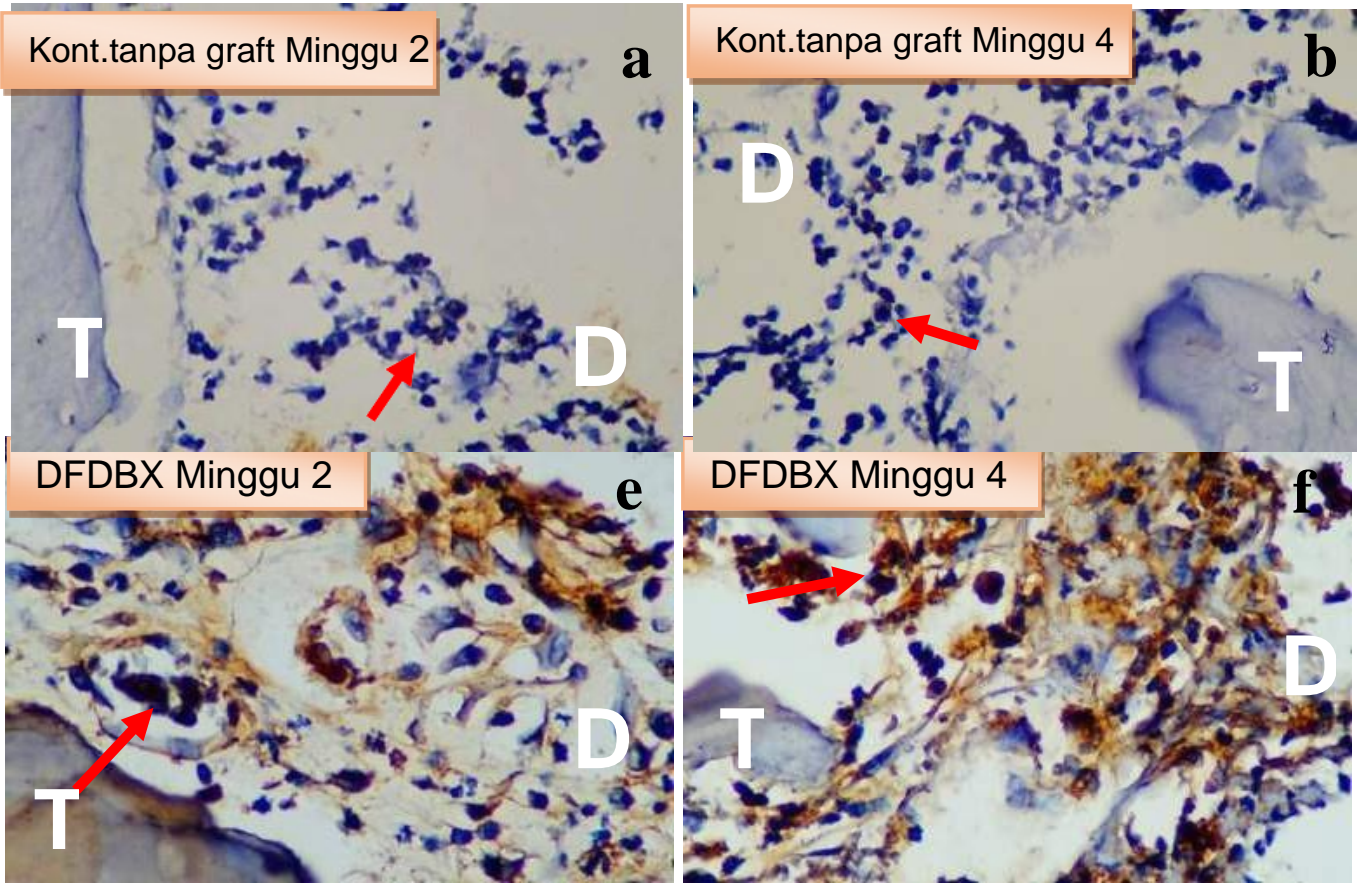

Figure 2 Microscopic view of osteoblasts expressing RUNX2 weeks 2 and 4 in the control group without graft, BHA and DFDBX. (a) Osteoblasts in the control group without graft week 2 (b) Osteoblasts in the control group without graft week 4 (c) Osteoblasts in the BHA group week 2 (d) Osteoblasts in the BHA group week 4 (e ) Osteoblasts in the 2nd week DFDBX group (f) Osteoblasts in the 4th week DFDBX group.

The results of the examination of osteocalcin expression in the control group without graft, BHA and DFDBX groups at weeks 2 and 4 are shown in Figure 3. Osteoblasts expressing osteocalcin indicate the number of mature osteoblasts in the defect area. The increase in the distribution of osteoblasts was most evident in the DFDBX group, followed by BHA and the control group without graft. Osteoblasts expressing osteocalcin are indicated by red arrows

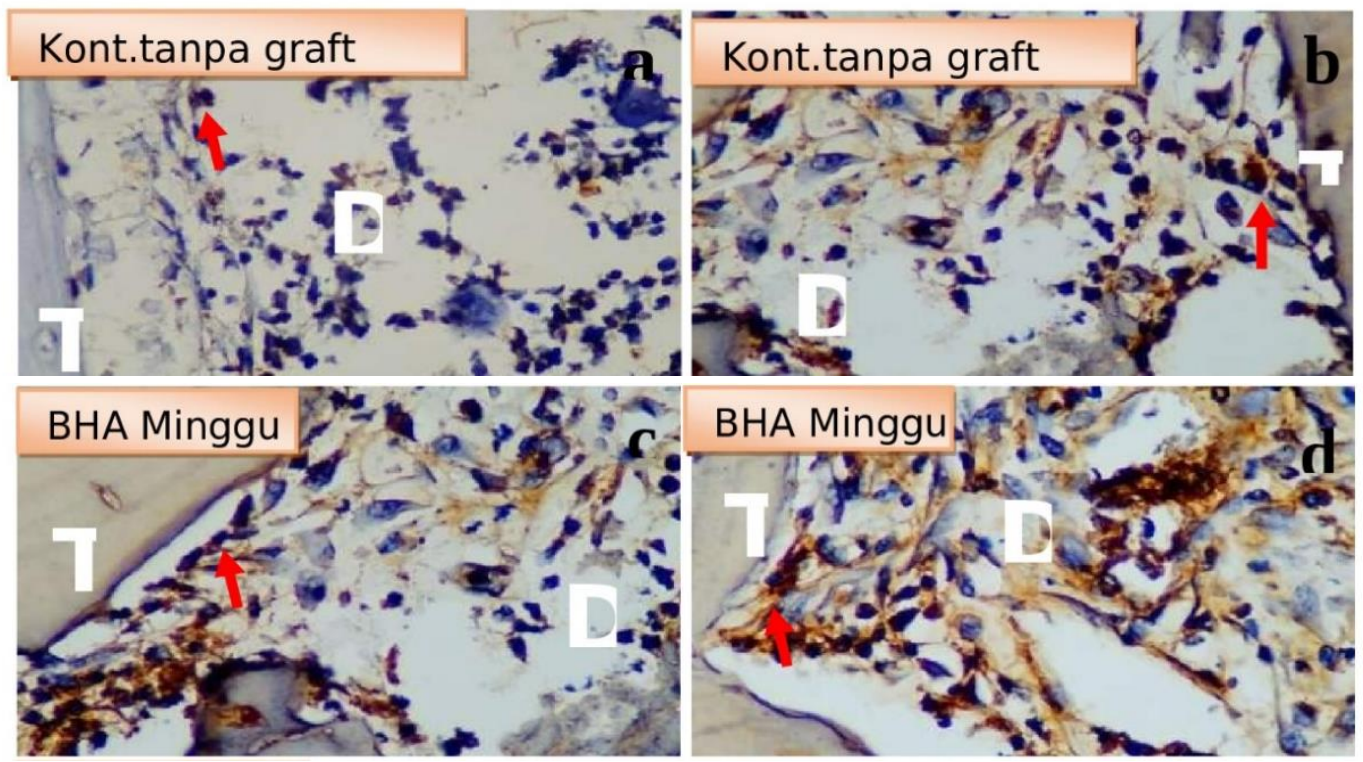




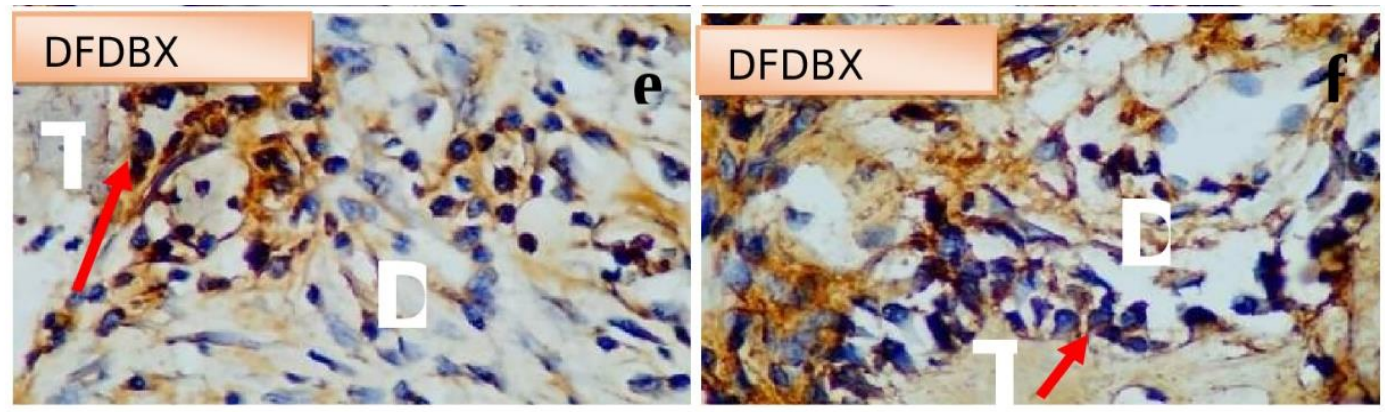

Figure 3 Microscopic view of osteoblasts expressing Osteocalcin week 2 and 4 in the Control group without graft, BHA and DFDBX. (a) Osteoblasts in the control group without graft week 2 (b) Osteoblasts in the control group without graft week 4 (c) Osteoblasts in the BHA group week 2 (d) Osteoblasts in the BHA group week 4 (e ) Osteoblasts in the 2nd week DFDBX group (f) Osteoblasts in the 4th week DFDBX group.

This examination was carried out by immunohistochemical staining to evaluate the expression of RUNX2 in each treatment group.
The results of the immunohistochemical examination of RUNX2 expression in each treatment group showed a different pattern.

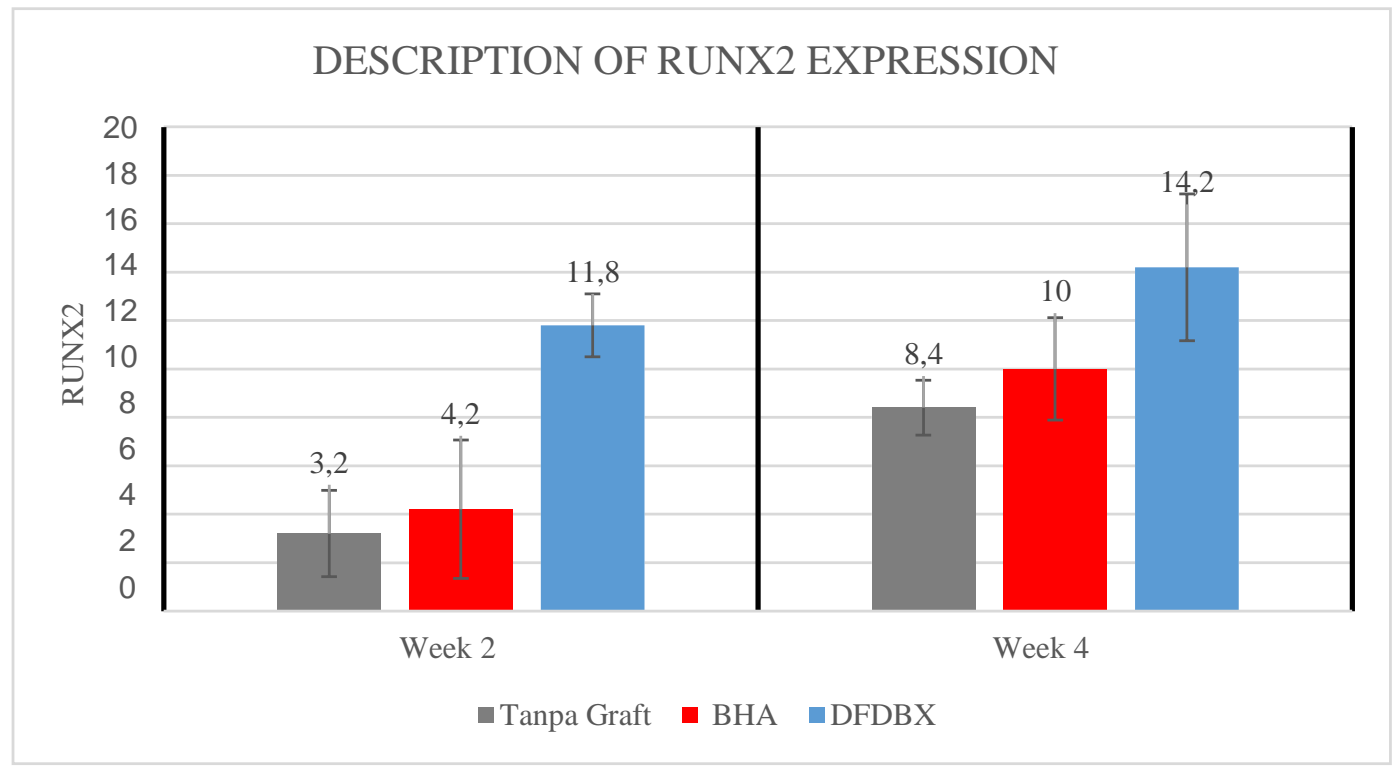

Figure 4. Description of RUNX2 expression variables in the DFDBX group, BHA group and the control group without graft at 2 and 4 weeks

Observation of RUNX2 expression between 2 and 4 weeks showed that the treatment group with DFDBX showed higher RUNX2 expression than the BHA group and the control group without graft. 
Table 1 Distribution of data and different tests between the control group without graft, the BHA group and the DFDBX group on RUNX2 expression

\begin{tabular}{|c|c|c|c|c|c|c|c|}
\hline \multirow{2}{*}{$\begin{array}{l}\text { Kelompok } \\
\text { perlakuan }\end{array}$} & \multirow{2}{*}{ Mean } & \multirow[b]{2}{*}{$\operatorname{SD}( \pm)$} & \multirow[b]{2}{*}{$\begin{array}{c}\text { Uji } \\
\text { Saphiro } \\
\text { Wilk }\end{array}$} & \multirow[b]{2}{*}{$\begin{array}{c}\text { Uji } \\
\text { Kruskal } \\
\text { Wallis }\end{array}$} & \multicolumn{3}{|c|}{ Uji Man Whitney U } \\
\hline & & & & & $\begin{array}{c}\text { Kontrol } \\
\text { Tanpa } \\
\text { graft } \\
\end{array}$ & $\begin{array}{c}\text { Kelompok } \\
\text { BHA }\end{array}$ & $\begin{array}{c}\text { Kelompok } \\
\text { DFDBX }\end{array}$ \\
\hline \multicolumn{8}{|c|}{ Ekspresi RUNX2 Minggu ke-2 } \\
\hline $\begin{array}{c}\text { Kontrol } \\
\text { tanpa graft }\end{array}$ & 3.2 & 1.78885 & $0,046^{*}$ & \multirow{3}{*}{$0,007 * *$} & & 0,572 & $0,008 * * *$ \\
\hline $\begin{array}{c}\text { Kelompok } \\
\text { BHA }\end{array}$ & 4,2 & 2.86356 & 0,087 & & & & $0,008 * * *$ \\
\hline $\begin{array}{c}\text { Kelompok } \\
\text { DFDBX }\end{array}$ & 11,8 & 1.30384 & 0,421 & & & & \\
\hline \multicolumn{8}{|c|}{ Ekspresi RUNX2 Minggu ke-4 } \\
\hline $\begin{array}{c}\text { Kontrol } \\
\text { tanpa graft }\end{array}$ & 8,4 & 1.14018 & 0,568 & \multirow{3}{*}{$0,019 * *$} & & 0,203 & $0,008 * * *$ \\
\hline $\begin{array}{c}\text { Kelompok } \\
\text { BHA }\end{array}$ & 10 & 2.12132 & 0,468 & & & & 0,055 \\
\hline $\begin{array}{c}\text { Kelompok } \\
\text { DFDBX }\end{array}$ & 14,2 & 3.03315 & 0,220 & & & & \\
\hline
\end{tabular}

Description :

* Data distribution is not normal $(\mathrm{p}<0.05)$ on the Saphiro Wilk test

** there is a significant difference $(\mathrm{p}<0.05)$ in the Kruskal Wallis test

$* * *$ there is a significant difference $(\mathrm{p}<0.05)$ in the Man Whitney U . test

In the statistical test (table 5.1), the RUNX2 expression data in the Saphiro Wilk test in the control group without graft at week 2 was 0.046. If assuming $\mathrm{p}<0.05$, it can be concluded that the data distribution is not normal. In the Kruskal Wallis test, $\mathrm{p}$ value was obtained in all groups at week 2 (0.007) and week 4 (0.019), assuming there was a significant difference if $p$ $<0.05$.

The results of the different Mann-Whitney test showed a significant difference $(p<0.05)$ in
RUNX2 expression between the control group without DFDBX graft and the DFDBX group (0.008) at week 2 and 4, respectively. Comparison between the BHA group and the control group without graft showed no significant difference in RUNX2 expression at the two observation times, week 2 (0.572) and week 4 (0.203).

The results of immunohistochemical examination of osteocalcin expression in each treatment group showed a different pattern. 


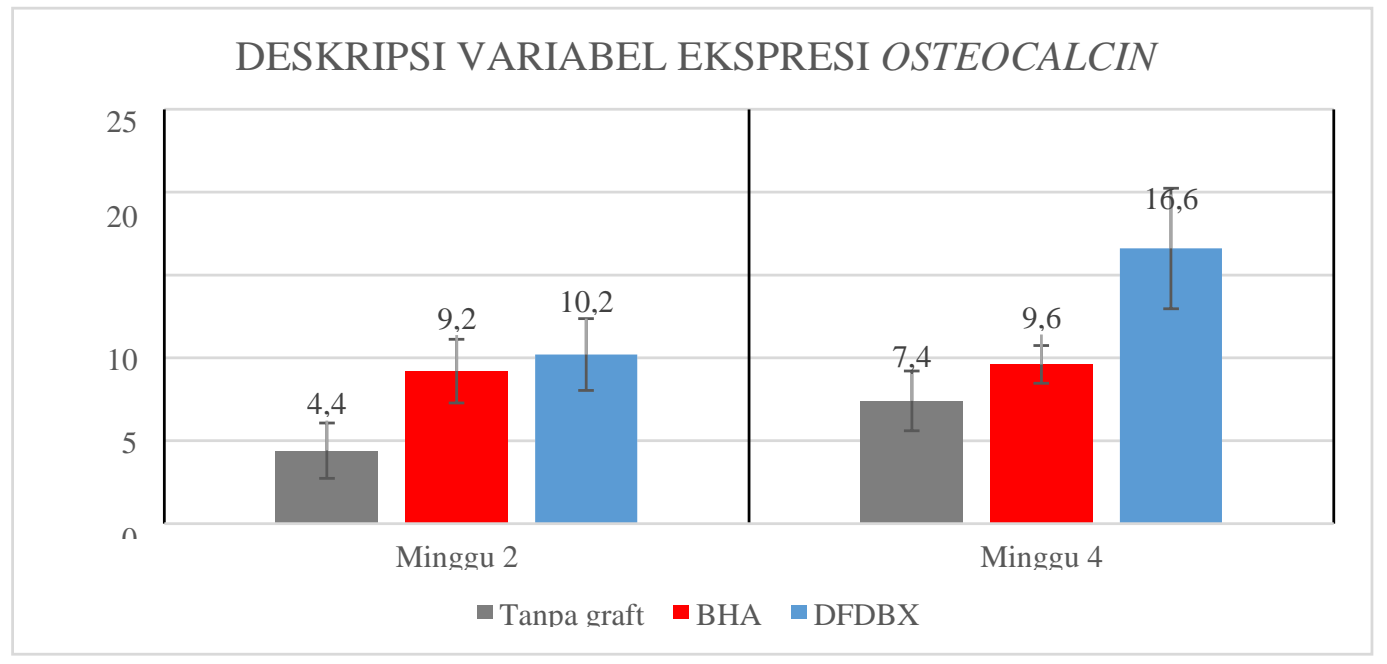

Figure 5 Description of Osteocalcin expression variables in the DFDBX group, the BHA group and the control group without graft at 2 and 4 weeks

In Figure 5, the observation of osteocalcin expression between weeks 2 and 4 shows that the treatment group with DFDBX showed higher osteocalcin expression than the BHA group and the control group without graft. At week 4, the highest osteocalcin expression was in the DFDBX treatment group (20), followed by the BHA group (14.4) and the lowest was the control group without graft (8.4).

Table 2 Distribution of data and different tests between the control group without graft, the BHA group and the DFDBX group on the expression of osteocalcin

\begin{tabular}{|c|c|c|c|c|c|c|c|}
\hline \multirow[b]{2}{*}{$\begin{array}{l}\text { Kelompok } \\
\text { perlakuan }\end{array}$} & \multirow[b]{2}{*}{ Mean } & \multirow[b]{2}{*}{ SD $( \pm)$} & \multirow{2}{*}{$\begin{array}{c}\text { Uji } \\
\text { Saphiro } \\
\text { Wilk }\end{array}$} & \multirow{2}{*}{$\begin{array}{c}\text { Uji } \\
\text { Kruskal } \\
\text { Wallis }\end{array}$} & \multicolumn{3}{|c|}{ Uji Mann-Whitney $U$} \\
\hline & & & & & $\begin{array}{c}\text { Kontrol } \\
\text { tanpa } \\
\text { graft }\end{array}$ & $\begin{array}{c}\text { Kelompok } \\
\text { BHA }\end{array}$ & $\begin{array}{c}\text { Kelompok } \\
\text { DFDBX }\end{array}$ \\
\hline
\end{tabular}

\section{Ekspresi Osteocalcin Minggu ke-2}

\begin{tabular}{|c|c|c|c|c|c|c|c|}
\hline $\begin{array}{c}\text { Kontrol } \\
\text { tanpa graft }\end{array}$ & 7,6 & 1.34164 & 0,314 & & & $0,016^{* * *}$ & $0,008^{* * *}$ \\
\hline $\begin{array}{c}\text { Kelompok } \\
\text { BHA }\end{array}$ & 10,8 & 1.30384 & 0,223 & \multirow{2}{*}{$0,012^{* * *}$} & & & 1,0 \\
\hline $\begin{array}{c}\text { Kelompok } \\
\text { DFDBX }\end{array}$ & 18,4 & 3.28634 & $0,005^{*}$ & & & & \\
\hline
\end{tabular}

Ekspresi Osteocalcin Minggu ke-4

\begin{tabular}{|c|c|c|c|c|c|c|c|}
\hline $\begin{array}{c}\text { Kontrol } \\
\text { tanpa graft }\end{array}$ & 8.4 & 2.16795 & 0,254 & & & 0,055 & $0,009 * * *$ \\
\hline $\begin{array}{c}\text { Kelompok } \\
\text { BHA }\end{array}$ & 14,4 & 2.88097 & 0,814 & \multirow{2}{*}{$0,004 * *$} & & & $0,009 * * *$ \\
\cline { 1 - 3 } $\begin{array}{c}\text { Kelompok } \\
\text { DFDBX }\end{array}$ & 20 & 2.64575 & 0,884 & & & & \\
\cline { 2 - 3 }
\end{tabular}

Description :

* Data distribution is not normal $(\mathrm{p}<0.05)$ on the Saphiro Wilk test

$* *$ there is a significant difference $(\mathrm{p}<0.05)$ in the Kruskal Wallis test

*** there is a significant difference $(\mathrm{p}<0.05)$ in the Man Whitney $\mathrm{U}$. test 
In the statistical test table 5.2, the data on the expression of osteocalcin in the Saphiro Wilk test in the DFDBX group for the 2nd week of the week was 0.005 . In the Kruskal Wallis test, p value ( $\mathrm{p}$ value) was obtained in all groups at week 2 (0.012) and week 4 (0.004). If assuming $p<0.05$ there was a significant difference, it can be concluded that there was a significant difference in osteocalcin expression between all treatment groups and control groups at the 2nd and 4th

\section{DISCUSSION}

In this study, the ossification process was observed by looking at the expression of RUNX2 and Osteocalcin as one of the biomarkers of bone metabolism. RUNX2 is often described as a major regulator of osteoblastogenesis, acting on the induction, proliferation and maturation of osteoblasts and controlling the expression of several osteoblastic genes (Bab et al., 2012).

RUNX2 was detected in all bone examinations, both in the process of embryonic formation and the mechanism of ossification (intramembranous/endochondral), presumably because RUNX2 regulates the expression of multiple genes in osteoblast development. RUNX2 is also a promoter of genes such as Osteocalcin, type I collagen and Osteopontin (Bruderer et al., 2014).

In this study, the results of the different test between groups (Mann Whitney U test) with $\mathrm{p}<0.05$ showed that the expression of RUNX2 in the second week showed a significant difference weeks.

From the results of the Mann-Whitney U test, there was a significant difference $(p<0.05)$ in the expression of Osteocalcin between the control group without graft and the DFDBX group at week 2 (0.008) and week 4 (0.009). The expression of osteocalcin was not significantly different between the BHA group and the DFDBX group at week 2 (1.0) but significantly different at week 4 (0.009).

between the expression of RUNX2 DFDBX and BHA (0.008), and at week 4 it was found that the expression of RUNX2 was higher in DFDBX but there was no significant difference (0.055). The comparison between the BHA group and the control group without graft also showed no difference in expression at the two observations at week $2(0.572)$ and week $4(0.203)$. This indicates that the growth factor content in DFDBX causes DFDBX osteoblast differentiation to occur earlier than in BHA and the control group without graft. The difference in the amount of RUNX2 expression between DFDBX and BHA is due to the osteogenic potential of DFDBX which is related to the number of proteins contained in it as well as the potential for osteoinduction and the content of BMPs (Plata et al., 2002).

The difference in RUNX2 expression in DFDBX and BHA at week 2 showed that the role of BMP in DFDBX was very influential in accelerating osteoblast differentiation which was 
seen in the increase in osteoblasts expressing RUNX2 much higher than in BHA. According to (Ferdiansyah et al., 2011) who conducted a study on the administration of BHA to massive bone defects in the ulna, stated that in defects given BHA, complement cascade activation, platelet aggregation and release of granule contents occurred due to endothelial damage to blood vessels that occurred during bone cutting.

In the BHA group and the control group, there was no significant difference because in BHA which was only osteoconductive, while in the control group without graft, the osteoblasts formed in the defect only came from recipient osteoblasts at the edges of the defect and periosteum. Because critical size defects are defects that cannot heal on their own, the presence of the recipient's periosteum and osteoblasts plays an important role. This is in accordance with research conducted by Huh et al. (2006) who conducted research on the healing of critical size defects in the mandible of dogs showed the periosteum has a large capacity in the process of ossification and bone repair.

The difference in Osteocalcin expression between the DFDBX and BHA groups did not appear to be significantly different at week 2 (1.0) but significantly different at week 4 (0.009). This is because the application of DFDBX containing growth factor and BMP to bone defects can

\section{REFERENCE}

Agata, H., Asahina, I., Yamazaki, Y., Uchida, M., Shinohara, Y., Honda, M., Kagami, H., \& Ueda, M. (2007). Effective bone increase the proliferation of mature osteoblast cells, compared to BHA and the control group without graft.

In the BHA group and the control group without graft, there was a higher difference in osteocalcin expression in BHA but there was no significant difference at week $2(0.016)$ and at week $4(0.055)$. This is because the inorganic material of BHA in the tissue is able to support the attachment and proliferation of osteoblasts (Osteoconduction). On the network; These conditions are influenced by macro and micro structures including shape, geometry, porosity, granule size, and surface roughness (Dersot et al., 1995).

From the results of this study, it was found that the bone healing process in the DFDBX group was faster than the BHA group and the control group without graft. This is in accordance with research by (Aliabadi, 2012; Ferdiansyah et al., 2017) which states that bone healing in demineralized bone matrix is better than in hydroxyapatite. In the research of Kamadjaja et. al. (2017) also stated that demineralized freeze dried bovine cortical bone membrane has optimal potential as a guided bone regeneration membrane and can undergo gradual biodegradation and has biocompatibility that can be accepted by body tissues

engineering with peroisteum-derived cells. Journal Dental Research, 86(1), 79-83.

Aliabadi, A. (2012). Evaluation of the effect of bovine demineralized bone matrix and 
coralline hydroxyapatite on radial fracture healing rabbit. Journal Of Cell and Animal Biology, 6(7), 109-114.

Babbush, C. (2001). Dental Implans: the art and science. In Philadelphia:WB Saunders Company.

Bruderer, R., G Richard, M., Alini, M., \& Stoddart, M. (2014). Role and regulation Of RUNX2 in Osteogenesis. European Cells and Materials, 28, 269-286.

Dersot, J. M., Colombier, M. L., Lafont, J., Baroukh, B., Septier, D., \& Saffar, J. L. (1995). Multinucleated Giant Cells Elicited Around Hydroxyapatite Particles Implanted In Craniotomy Defects Are Not Osteoclasts. Anat, 242, 166-176.

Ferdiansyah, Djoko, R., Fedik, A. R., \& Aulani'am. (2011). Regenerasi pada massive bone defect dengan Bovine hydroxyapatite sebagai scaffold mesenchymal Stem cell. JBP, 13(3), 179195.

Ferdiansyah, Mahyudin, Utomo, Dwikora, N., Suroto, Heri, Martanto, Tri, W., Edward, Mouli, Gaol, \& Imelda, L. (2017). Comparative Effectiveness of Bone
Grafting Using xenograft Freeze-Dried Cortical Bovine, Allograft Freeze- Dried Cortical new Zealand White Rabbit, Xenograft Hydroxyapatite Bovine, and Xenograft Demineralized Bone Matrix Bovine in Bone Defect of Femoral D. International Journal of Biomaterial, 2017, 9. https://doi.org/7571523

Hallman, M., \& Thor, A. (2008). Bone substitutes and growth factors as an alternative/complement to autogenous bone for grafting in implant dentistry. Journal Compilation Periodontology, 47, 172-192. Lekovic, V., Kenney, E., \& Weinlaender, M. (2007). A bone regenerative approach to alveolar ridge maintenance following tooth extraction. Report of 10 Cases. J Periodontol, 65, 563-570.

Plata, D. V, Scheyer, E. T., \& Mellonig, J. T. (2002). Clinical comparison of an enamel matriw derivative used alone or in combination with a bovine- derived xenograft for treatment of periodontal osseous defect in humans. Journal Periodontal, 73, 433-440. 